\title{
An international, interprofessional investigation of the self-reported podcast listening habits of emergency clinicians: A METRIO Study
}

\author{
Brent Thoma (1), MD, MA, MSc*; Scott Goerzen ${ }^{\dagger}$; Timothy Horeczko, MD, MSCR ${ }^{\ddagger}$; Damian Roland, \\ BMedSci, BMBS, MRCPCH, PhDI\|; Andrew Tagg, MBBS ${ }^{* *++}$; Teresa M Chan (D), MD, MHPE ${ }^{\S \S \uparrow ; ; ~}$ \\ Stevan Bruijns, MBChB, DipPEC, MPhil, PhDIll; Jeff Riddell, MD***; The METRIQ Podcast Study \\ Collaborators
}

\section{CLINICIAN'S CAPSULE}

What is known about the topic?

Podcasts are used broadly by emergency clinicians for education.

What did this study ask?

How and why podcasts are used by emergency medicine and critical care clinicians?

What did this study find?

Participants most frequently listened to medical podcasts to review new literature, learn core material, and refresh memory; few utilize active learning strategies, and most conduct other activities while listening.

Why does it matter to clinicians?

Learners may consider utilizing active learning techniques while listening to podcasts; podcast producers may encourage the use of active learning techniques.

\section{ABSTRACT}

Objectives: Podcasts are increasingly being used for medical education. A deeper understanding of usage patterns would inform both producers and researchers of medical podcasts. We aimed to determine how and why podcasts are used by emergency medicine and critical care clinicians.
Methods: An international interprofessional sample (medical students, residents, physicians, nurses, physician assistants, and paramedics) was recruited through direct contact and a multimodal social media (Twitter and Facebook) campaign. Each participant completed a survey outlining how and why they utilize medical podcasts. Recruitment materials included an infographic and study website.

Results: 390 participants from 33 countries and 4 professions (medicine, nursing, paramedicine, physician assistant) completed the survey. Participants most frequently listened to medical podcasts to review new literature $(75.8 \%)$, learn core material $(75.1 \%)$, and refresh memory $(71.8 \%)$. The majority $(62.6 \%)$ were aware of the ability to listen at increased speeds, but most $(76.9 \%)$ listened at $1.0 \mathrm{x}$ (normal) speed. All but $25(6.4 \%)$ participants concurrently performed other tasks while listening. Driving (72.3\%), exercising $(39.7 \%)$, and completing chores $(39.2 \%)$ were the most common. A minority of participants used active learning techniques such as pausing, rewinding, and replaying segments of the podcast. Very few listened to podcasts multiple times.

Conclusions: An international cohort of emergency clinicians use medical podcasts predominantly for learning. Their listening habits (rarely employing active learning strategies and frequently performing concurrent tasks) may not support this goal. Further exploration of the impact of these activities on learning from podcasts is warranted.

From *Department of Emergency Medicine at the University of Saskatchewan, Saskatoon, SK, Canada; †College of Medicine at the University of Saskatchewan, Saskatoon, SK, Canada; łLos Angeles County Harbor-University of California, Los Angeles Medical Center, Los Angeles, California; $\S$ David Geffen School of Medicine at the University of California, Los Angeles, Los Angeles, California; ISAAPHIRE Group, University of Leicester, Leicester, England; „Paediatric Emergency Medicine, Leicester Royal Infirmary, Leicester, England; **Emergency Medicine, Footscray Hospital, Melbourne, Australia; ††University of Melbourne; §§Division of Emergency Medicine, Department of Medicine at McMaster University, Hamilton, Ontario, Canada; ТףTMcMaster Program for Education Research, Innovation, and Theory (MERIT), Hamilton, Ontario; ||||Division of Emergency Medicine, University of Cape Town, Cape Town, South Africa; and the ${ }^{* *}$ Clinical Emergency Medicine, Keck School of Medicine at the University of Southern California, Los Angeles, California.

Correspondence to: Dr. Brent Thoma, Room 2646, Box 16, 103 Hospital Drive, Saskatoon, SK S7N 0W8; Email: brent.thoma@usask.ca 


\section{RÉSUMÉ}

Objectif: Le recours à la baladodiffusion est de plus en plus fréquent en formation médicale. Une meilleure compréhension des habitudes d'utilisation des balados éclairerait les producteurs de contenu médical et les chercheurs. L'étude visait donc à déterminer comment et pourquoi la baladodiffusion est utilisée par les praticiens de la médecine d'urgence et de la médecine intensive.

Méthode: L'équipe a fait appel aux relations personnelles directes et à une stratégie multimodale de recherche dans les médias sociaux (Twitter et Facebook) pour former un échantillon international et interprofessionnel (étudiants en médecine, résidents, médecins, infirmiers, adjoints aux médecins et ambulanciers paramédicaux) de participants. Chacun devait remplir un questionnaire en ligne sur la manière dont il utilisait les balados en médecine et les raisons pour lesquelles il employait cette méthode. Le matériel servant à la recherche de participants comprenait un site web sur l'étude et un document infographique.

Résultats: Au total, 390 participants, provenant de 33 pays et pratiquant dans 4 professions (médecine, soins infirmiers, paramédecine, médecine auxiliaire), ont rempli le questionnaire. Le plus souvent, les répondants écoutaient du contenu médical en baladodiffusion pour repasser de la nouvelle documentation $(75,8 \%)$, pour apprendre du contenu de base $(75,1 \%)$ et pour se rafraîchir la mémoire $(71,8 \%)$. La majorité des participants $(62,6 \%)$ connaissaient les possibilités d'écoute en accéléré, mais la plupart $(76,9 \%)$ préféraient l'écoute à vitesse normale $(1,0 \mathrm{x})$. Tous, à l'exception de 25 répondants $(6,4 \%)$, faisaient autre chose pendant qu'ils écoutaient les fichiers, notamment conduire (72,3\%), faire de l'activité physique $(39,7 \%)$ ou effectuer des tâches ménagères $(39,2 \%)$. Une minorité de participants appliquaient toutefois des techniques d'écoute active, telles que pauses, retours rapides ou réécoute, à des fins d'apprentissage. Très peu écoutaient à plusieurs reprises du contenu baladodiffusé.

Conclusions: II ressort de l'enquête menée dans la cohorte internationale que les praticiens des soins d'urgence utilisent principalement les balados à des fins d'apprentissage. Toutefois, leurs habitudes d'écoute (peu d'écoute active et beaucoup de tâches concomitantes) peuvent ne pas favoriser l'atteinte du but visé. Aussi serait-il justifié d'examiner l'incidence des activités concurrentes sur l'apprentissage par baladodiffusion.

Keywords: Education, emergency medicine, research

\section{INTRODUCTION}

Educational podcasts have become popular platforms for teaching and learning in medical education ${ }^{1,2}$ and are one of the most-utilized educational resource among emergency medicine residents. ${ }^{3,4}$ However, it is unclear how they are used or if they could be used most effectively for learning. The educational literature provides broad support for the superiority of active learning. ${ }^{5}$ The inherently passive nature of podcasts may limit their effectiveness. ${ }^{6}$ Few studies have explored nuanced listening behaviours such as whether listeners use active learning methods such as note-taking, pausing, or repeating segments for processing. ${ }^{7,8}$ Given the scant work done to characterize the use of podcasts by a broader group of practicing clinicians and the uncertainty around the active use of podcasts, we sought to characterize usage patterns and listening behaviours of an international cohort of emergency medicine and critical care clinicians.

\section{METHODS}

We performed a cross-sectional survey to determine how podcasts are used by emergency and critical care clinicians recruited through a multimodal online sampling strategy. The study was exempted from ethical review by the Research Ethics Board at the University of Saskatchewan (BEH 17-170).

Our international authorship team aimed to recruit an international sample of participants. After a literature review, two authors (BT and SG) developed survey questions in accordance with current best practices in survey design. ${ }^{9}$ Five other study authors with experience in medical podcasting reviewed and edited the questionnaire to ensure relevance to the constructs of interest. The survey was piloted by the authors of FluidSurvey software in August 2017. The pilot resulted in minor modifications to the survey, including adding questions, shortening the number of questions per survey page, and refining of the wording of existing questions.

We followed the Medical Education Translational Resources: Impact and Quality (METRIQ) Study's participant recruitment process to recruit a cohort of emergency clinicians who listen to podcasts. ${ }^{10}$ This included sharing an infographic (Appendix A) on email, Facebook, and Twitter; using the \#FOAMed hashtag on Twitter to target a virtual community of emergency and critical care clinicians; and recruiting from our personal networks using email. We also invited 


\begin{tabular}{|c|c|c|}
\hline & Variable & $n(\%)$ \\
\hline \multirow{7}{*}{$\begin{array}{l}\text { Activities generally } \\
\text { performed while } \\
\text { listening to podcasts }\end{array}$} & Driving & $284(72.8)$ \\
\hline & Exercise & 155 (39.7) \\
\hline & Chores & $153(39.2)$ \\
\hline & Other (unclassified) & 49 (12.6) \\
\hline & Other (walking) & $18(5.8)$ \\
\hline & Other (public transit) & $9(2.9)$ \\
\hline & None & $25(6.4)$ \\
\hline \multirow{5}{*}{$\begin{array}{l}\text { Frequency of note-taking } \\
\text { while listening to } \\
\text { podcasts }\end{array}$} & Never & $271(69.5)$ \\
\hline & One-fourth of the time & $90(23.1)$ \\
\hline & One-half of the time & $21(5.4)$ \\
\hline & Three-fourths of the time & $3(0.8)$ \\
\hline & Always & $5(1.3)$ \\
\hline \multirow{6}{*}{$\begin{array}{l}\text { Frequency of pausing } \\
\text { podcasts while listening }\end{array}$} & Never & $31(7.9)$ \\
\hline & Rarely & 127 (32.3) \\
\hline & One-fourth of the time & $102(26.0)$ \\
\hline & One-half of the time & $65(16.5)$ \\
\hline & Three-fourths of the time & $18(4.6)$ \\
\hline & Nearly every podcast & $50(12.7)$ \\
\hline \multirow{5}{*}{$\begin{array}{l}\text { Reasons for pausing the } \\
\text { podcast }\end{array}$} & Listening was interrupted & $285(72.5)$ \\
\hline & $\begin{array}{l}\text { To allow the processing } \\
\text { of content }\end{array}$ & $178(45.3)$ \\
\hline & $\begin{array}{l}\text { To break up podcasts into } \\
\text { digestible segments }\end{array}$ & 125 (31.8) \\
\hline & $\begin{array}{l}\text { To allow memorization of } \\
\text { information }\end{array}$ & $63(16.0)$ \\
\hline & Other & $23(5.9)$ \\
\hline \multirow{6}{*}{$\begin{array}{l}\text { Frequency of replaying } \\
\text { segment of podcasts }\end{array}$} & Never & $40(10.2)$ \\
\hline & Rarely & 135 (34.4) \\
\hline & One-fourth of the time & 122 (31.0) \\
\hline & One-half of the time & 48 (12.2) \\
\hline & Three-fourths of the time & $23(5.9)$ \\
\hline & Nearly every time & $25(6.4)$ \\
\hline \multirow[t]{4}{*}{$\begin{array}{l}\text { Reason for replaying } \\
\text { segments of podcasts }\end{array}$} & $\begin{array}{l}\text { To ensure information } \\
\text { wasn't missed }\end{array}$ & $225(57.3)$ \\
\hline & $\begin{array}{l}\text { I know I missed } \\
\text { information }\end{array}$ & $203(51.7)$ \\
\hline & To reinforce information & $202(51.4)$ \\
\hline & Other & $19(4.8)$ \\
\hline \multirow{6}{*}{$\begin{array}{l}\text { Frequency of repeating } \\
\text { entire podcasts }\end{array}$} & Never & $95(24.2)$ \\
\hline & Rarely & $206(52.4)$ \\
\hline & One-fourth of the time & $67(17.0)$ \\
\hline & One-half of the time & $17(4.3)$ \\
\hline & Three-fourths of the time & $4(1.0)$ \\
\hline & Nearly every time & $4(1.0)$ \\
\hline \multirow{4}{*}{$\begin{array}{l}\text { Reason for repeating entire } \\
\text { podcasts }\end{array}$} & To reinforce information & $232(59.0)$ \\
\hline & $\begin{array}{l}\text { I know I missed } \\
\text { information }\end{array}$ & $88(22.4)$ \\
\hline & $\begin{array}{l}\text { To ensure information } \\
\text { wasn't missed }\end{array}$ & 78 (19.8) \\
\hline & Other & $34(8.7)$ \\
\hline
\end{tabular}

collaborators from a previously published series of METRIQ studies using email. ${ }^{10}$

Recruitment material directed prospective participants to an intake form (Supplemental Material Appendix B) hosted at https://METRIQstudy.org. The intake form collected the name, email, profession, and level of training of prospective participants. Its completion was considered an expression of interest in the study. A link to the study survey was sent to prospective participants within 24 hours of completing the intake form. Reminder emails were sent every 1-2 weeks, up to a maximum of four times. The initial email was sent by SG, and follow-up emails were sent by BT. To incentivize participation, participants who completed the METRIQ podcast study were acknowledged as collaborators.

Participants formally enrolled in the study by completing a form at the beginning of the survey (Supplemental Material Appendix C) that contained the study consent. Raw survey data were exported from FluidSurveys, and descriptive statistics were calculated using Excel (Microsoft Corp., Redmond, WA, USA).

\section{RESULTS}

Recruitment occurred between September 10 and December 9, 2017. The survey remained accessible until March 8, 2018. Four hundred fifty-seven health care professionals expressed interest: 394 (86.2\%) formally enrolled, and 390 (85.3\%) completed the survey. The average age of the participants was 33.3 years (standard deviation [SD] 8.8), with a slight male predominance (54.8\%) (Supplemental Material Appendix D). While most were from North America (68.7\%), participants represented 34 countries. A majority $(59.4 \%)$ of study participants (attending physicians, nurses, paramedics, and physician assistants) represented populations whose use of medical podcasts had not been described previously. Non-physicians (nurses, paramedics, and physician assistants) comprised $31.7 \%$ of the population. A minority $(9.7 \%)$ of participants managed, owned, or operated their own podcast. Most listened to podcasts at least monthly $(79.0 \%)$.

Participants cited multiple reasons why they listened to medical podcasts. There was significant overlap in those who used them to review the literature $(75.8 \%)$, learn core material $(75.1 \%)$, and refresh memory (71.8\%). Inspiration (45.5\%), entertainment (40.7\%), and connecting with the community $(36.4 \%)$ were also 
cited as reasons for listening by a minority of participants.

Most (93.6\%) participants performed other activities while listening. Driving (72.8\%), exercise (39.7\%), and chores $(39.2 \%)$ were the most frequent activities (Table 1). The use of active learning strategies was variable. Few participants took notes while listening $(69.5 \%$ never; $23.1 \%$ "about one-fourth of the time"). Many $(60.3 \%)$ reported pausing podcasts at least one-fourth of the time, but this was most often because they were interrupted $(72.5 \%)$ and only rarely to allow processing of content $(45.3 \%)$ or memorization $(16.0 \%)$. Replaying parts of podcasts was more common than replaying entire episodes.

Despite the finding that most $(61.8 \%)$ of the participants were aware that they could change the listening speed of podcasts, just under one-quarter of participants (23.1\%) did so, with most (76.1\%) opting to listen at $1.0 \times$ (normal) speed.

\section{DISCUSSION}

This study aimed to focus future research by understanding how and why emergency and critical care clinicians consume podcasts for education. It is unique among the few descriptive studies on related topics that have been published both because of its international and interprofessional participant pool and its investigation of how clinicians are using podcasts.

Our findings may help medical educators and podcast producers to understand their learners and listeners better in the domains of demographics, concurrent activity, motivations for listening, frequency of consumption, and active learning strategies employed. The results suggest that medical content focused on reviewing and learning clinical material is extremely important. Consistent with developing theories on the role of educational entertainment, ${ }^{11}$ a subgroup of participants endorsed a desire to be inspired and entertained. The finding that greater than one-third of participants listened to podcasts to foster a sense of community may have been inflated by our recruitment methodology, which specifically sought out participants in a community of practice. However, it is consistent with qualitative explanations of the listening motivations of residents. ${ }^{12}$

While most participants listened with the goal of learning from podcasts, this contrasted with their behaviours while listening. It is likely that unrecognized inattention while conducting other activities is detrimental to retention. Only a minority used active learning strategies that could aid retention (e.g., notetaking, pausing, repeating segments, and repeating episodes). ${ }^{5-8}$ Research exploring the impact of concurrent task completion and active learning techniques on the retention of podcast content is needed. For now, listeners could consider trying these techniques while podcast producers could encourage them within their recordings.

As a survey-based study with a social media-based recruitment strategy, our results have numerous limitations. This is the largest study to date on this topic and the only one to include multiple professions and an international sample. However, we could not calculate a traditional response rate because of the recruitment methodology, ${ }^{10}$ and the characteristics of the population of interest (emergency and critical care clinicians who listen to podcasts regularly) were not available to compare with our sample. As $9.7 \%$ of our participants managed, owned, or operated their own podcast and a significant proportion were recruited from the authors' personal networks, the sample might not have been representative of this group. Finally, our sample was limited to those with English-language proficiency who resided in countries with enough internet bandwidth to allow for podcast downloading or streaming. This likely contributed to the high proportion of participants from developed, Englishspeaking countries.

\section{CONCLUSION}

Emergency clinicians use medical podcasts predominantly for learning. Most perform concurrent tasks, and few utilize active learning strategies. Several active learning techniques were used by a minority of participants that could be adopted more broadly and encouraged by podcast producers. Further exploration of the effectiveness of these techniques should be explored.

\section{SUPPLEMENTARY MATERIAL}

The supplementary material for this article can be found at https://doi.org/10.1017/cem.2019.427.

Acknowledgement: The authors would like to acknowledge Annet Alenyo Ngabirano and Katie Knight for their assistance with participant recruitment.

Competing interests: SG received a Dean's Summer Research Project Grant from the University of Saskatchewan to support 
his contributions to this work. Several of the authors currently or previously contributed to emergency medicine podcasts. None were compensated for their work on these podcasts.

\section{REFERENCES}

1. Cadogan M, Thoma B, Chan TM, Lin M. Free Open Access Meducation (FOAM): the rise of emergency medicine and critical care blogs and podcasts (2002-2013). Emerg Med 7 2014;31 e1:e76-7.

2. Cho D, Cosimini M, Espinoza J. Podcasting in medical education: a review of the literature. Korean 7 Med Educ 2017;29 (4):229-39.

3. Purdy E, Thoma B, Bednarczyk J, Migneault D, Sherbino J. The use of free online educational resources by Canadian emergency medicine residents and program directors. CFEM 2015;17(2):101-6.

4. Riddell J, Swaminathan A, Lee M, et al. A Survey of Emergency Medicine Residents' Use of Educational Podcasts. West 7 Emerg Med 2017;18(2):229-34.

5. Prince M. Does active learning work? A review of the research. 7 Eng Educ 2004;93(3):223-32.

6. Zanussi L, Paget M, Tworek J, McLaughlin K. Podcasting in medical education: can we turn this toy into an effective learning tool? Adv Health Sci Educ Theory Pract 2012;17(4): 597-600.

7. Hargis J, Schofield K, Wilson D. Fishing for learning with a podcast net. i-manager's 7 . Educ Technol. 2008;4 (4):33-8.

8. Scutter S, Stupans I, Sawyer T, King S. How do students use podcasts to support learning? Australas 7 Educ Technol 2010;26(2):180-91.

9. Artino Jr AR, La Rochelle JS, Dezee KJ, Gehlbach H. Developing questionnaires for educational research: AMEE Guide No. 87. Med Teach 2014;36(6):463-74.

10. Thoma B, Paddock M, Purdy E, et al. Leveraging a virtual community of practice to participate in a survey-based study: A description of the METRIQ Study Methodology. AEM Educ Train 2017;1(2):110-3.

11. Moyer-Gusé E. Toward a theory of entertainment persuasion: explaining the persuasive effects of entertainmenteducation messages. Commun Theory 2008;18(3):407-25.

12. Riddell J, Robins L, Brown A, et al. Independent and interwoven: A qualitative exploration of residents' experiences with educational podcasts. Acad Med. 2019; epub, doi: 10.1097/ACM.0000000000002984

APPENDIX: The METRIO Podcast Study Collaborators (in alphabetical order by last name)

Peter Agaba, Mohammed M Aldawood, Mohammed Makki Aldawood, Mathew Alex, Salma Ali, Laura Allan, Mohammed Almuhanna, Ashwini Amaratunga,
Jeremy Amayo, Natalie Anderson, Omar Anjum, Mads Astvad, Arden Azim, Patrick Bafuma, Michelle Bailey, Steve Baker, Kimberly Baldino, Joanna Banaszek, Alex Barber, David Barton, Alan Batt, Rachel Baumgartner, Jared Baylis, Taylor Bechamp, Stéphanie Beckett, Chris Bell, Antônio Felippe Benini, Temesgen Beyene, Meghan Bhatia, Richard Biedermann, Märta Björling, Jessica Blackbourn, Michael Blanchard, Iria Miguens Blanco, Brandon Blondeau, Bryan Boling, Andrew Bowman, Emma Bradshaw, Victoria Brazil, Ian Breden, Page Bridges, Joshua Britton, Robert Bruce, Ineke Brummer, Wisarut Bunchit, Kevin Burns, Mike Butler, Alan C. Taylor, Avery Callahan, Federico Carini, Christina Castillo, Ryan Chadwick, Christie Wing Long Chan, Kathryn Chan, Teresa Chan, Alvin Chin, Rachel Christian, Alex Christiansen, Alyssa Cocchiara, Isabelle Colmers-Gray, Joe Colucci, Roberto Cosentini, Stefan Cowtan, Avery Crocker, Henry Cullen, Andrew D'alessandro, Bagonza I Kenneth Daniel, Aaron Danielson, Christi Denton, Alixe Dick, Susana Garcia Diez, Tatjana Dill, Matt Dionne, Anthony Doherty, Danielle Donoghue, Maia Dorsett, Dr Doug Lynch, Hugo Dowd, Philippe Dubuc-Gaudreau, Taylor Duda, Justin Dueweke, William Dunkerley, Kevin Durr, Marcia Edmonds, Sylvia Egels, Kirsty Ellis, Elaine Erasmus, Rebecca Erker, Caley Flynn, Mark Frederikse, Ushira Ganas, Joe Ghorayeb, Siew Pei Goh, Mark Goichman, Amanda Goodfellow, Puja Gopal, Michael Gottlieb, Paul Grinzi, Andrew Grock, Tanner Gronowski, Catriona Gunn, Adrianna Gunton, Andrew Hall, Benjamin Hardy, Lukas Hashem, Erfun Hatam, Philip Hehn, John Heisler, Chloe Henley, Suelin Hilbert, Sakura Hingley, Amy Ho, Nicholas Hochfelden, Brenden Hoff, Caroline Hoogerheide, Dirk Houtman, Lamont Hunter, Qasim Hussain, Elizabeth Namugaya Igaga, Pholaphat Charles Inboriboon, Aaron Inouye, Irene Ostapowich, Palbha Jain, Jesse Jamieson, Pieter Jan, Suneth Jayasekara, Dayna Jaynstein, Maria Jirwe, Levi Johnston, Will Johnston, Kalanzi Joseph, Clint Kalan, Kelly Kaley, Drew Kalnow, Annika Kamberelis, Ramya Kancherla, Aravind Kashyap, Gerben Keijzers, Catherine Kerr, Jaasmit Khurana, Jerry Kim, Katie Knight, Lisa Knijnenberg, Justin Koh, Melodie Kolmetz, Daniel Korpal, James Kozak, Alexander Krois, Ivanna Kruhlak, Natalia Krupin, Michael I Kruse, Stephen Kydd-Hindelang, Simon Lainh, Chip Lange, Bryan Laviolette, Jacqui Le Geyt, Andrew Leach, Jennifer Leckie, Charles Lei, Edgar Lei, Vivian Lei, Haakon Lenes, Nilantha Lenora, Mason Leschyna, Tim Leung, Ian Lewins, 
Resa E Lewiss, Winny Li, Kelly Lien, Brodie Lipon, Andrew Little, Jonathan Little, Steve Liu, Megan Loucks, Stephanie Louka, Jessica Gy Luc, S. LuckettGatopoulos, Kristopher Maday, Sonali Mantoo, Paige Mason, Rebecca Maxwell, Cian Mcdermott, Michael Mcdonnell, Jonathan Mcghee, Sean Mcintosh, Susan Mclellan, Amy Mcnaughtan, Carolyn Mcquarrie, Katie Mcpadden, Therese Mead, Patrick Meloy, Maartje Melse, Donna Mills, Brendan Moore, Justin Morgenstern, Lee Morissette, Sarah Mott, Pinaki Mukherji, Lisa Murphy, Victoria Myers, Vanessa Naidoo, Gabriel Najarro, Meera Nariadhara, Annet Alenyo Ngabirano, Dan Nguyen, Taylor Nikel, Anton Nikouline, Mais Nuaaman, Sean Nugent, Dayle Ostapiuk, Nadine Ouderkirk, Rob Paquin, Alim Pardhan, Ravi Parhar, Quinten Paterson, Christine Patterson, Caroline Chandler Pedrozo, Gina Pellerito, Brock Phillips, Sarah Plante, Zoe Polsky, Dawn Prall, Michael Prats, Joel Privé, Gregor Prosen, Henrique Alencastro Puls, Vishal Puri, Chichen Qiu, Tanis Quaife, Md, Salim R. Rezaie, Dillan Radomske, John Reagan, Elissa Remmer, Jeff Riddell, Milan Ridderikhof, Jamie Riggs, Brendan Riordan, Doreen Rivera, Isabel Rizor, Genevieve Robinson, Damian Roland, Kaye Rolls, Stuart Rose, Keith Rosenberg, Kyle Roshan Wong, Paul Ross, Brenda Ruberto, Evan Russell, Mackenzie Russell, Syed S Ahmed, Abdul Sattar Abdul Safras, Eleni Salakidou, Erin Sandilands, Michelle L Santos, Alan Sazama,
Owen Scheirer, Rebecca Schulman, Paul Schunk, Makamu Sebakeng, Ashley Selvig, Cornelius Sendagire, Alex Senger, Parisa Shahrabadi, Julia Sheffield, David Sheps, Jack Shier, Seyara Shwetz, Mansoor Siddiqui, Teresa Siefke, Sarah Simons, Adam Singer, Gabilan Sivapatham, Shyam Sivasankar, Sarah Skolfield, Sam Smith, Paula Sneath, Cassandra Sobkiw-Kurtz, Robert Soegtrop, Peter Speare, Jan Spicer, Anna Spinaze, Adrienne Stedford, James Stempien, Britni Sternard, Brittany Stewart, Katie Stuart, Danielle Swart, Colleen Sweeney, Henry Swoboda, Andrew Tagg, Christopher Tait, Nikhil Tambe, Elisha Targonsky, Michael Taylor, Robert Taylor, Luis Eduardo Vargas Téllez, Brent Thoma, Brent Thoma, Megan Thoma, Adam Thomas, Gareth Thomas, Liam Thorley, Gerhard Tiwald, Sydney Todorovich, Meriel Tolhurst-Cleaver, Luz-Patricia Torres, Max Tory, Charlene A Traynor, Seth Trueger, Troy Turner, Amol Utrankar, Italo Vasquez Vargas, Christopher Velasquez, René Verbeek, Femke Verbree, Jacqueline Vulto, Sonja Wakeling, Ateshia Walker, Gregory Wanner, Kevin Webb, Brittni Webster, Kristen Weersink, Hao Wei Chen, Meghan Wentzell, James Werbicki, Scott J Wieters, Gabby Wilcox, Penny Wilson, Nelson Wong, Mark Woodcroft, Jason Woods, Rob Woods, Nichole Woodward, Fred Wu, Craig Wylie, Kevin Wyne, Lisa Tai-Ling Ying, Louise Hammer Yndigegn, Heinri Zaayman, Leah Zhao, Katina Zheng, Alex Zozula 